\title{
Prognostic Role of the Platelet-to-Lymphocyte Ratio for Patients With Metastatic Colorectal Cancer Treated With Aflibercept
}

\author{
AKIHISA MATSUDA $^{1,2}$, TAKESHI YAMADA ${ }^{2}$, SATOSHI MATSUMOTO $^{1}$, \\ SEIICHI SHINJI ${ }^{2}$, RYO OHTA ${ }^{2}$, HIROMICHI SONODA ${ }^{2}$, ERIKO SHINOZUKA ${ }^{1}$, \\ KUMIKO SEKIGUCHI ${ }^{1}$, HIDEYUKI SUZUKI ${ }^{1}$ and HIROSHI YOSHIDA ${ }^{2}$ \\ ${ }^{1}$ Department of Surgery, Nippon Medical School Chiba Hokusoh Hospital, Inzai, Japan; \\ ${ }^{2}$ Department of Gastrointestinal and Hepato-Biliary-Pancreatic Surgery, Nippon Medical School, Tokyo, Japan
}

\begin{abstract}
Background/Aim: The efficacy of aflibercept plus 5fluorouracil, leucovorin and irinotecan (FOLFIRI) therapy has been demonstrated in patients with metastatic colorectal cancer $(m C R C)$ in global and Japanese clinical trials. However, a practical biomarker to predict its efficacy is lacking. Patients and Methods: This was a single-institution retrospective study of 21 patients with $m C R C$ consecutively treated with aflibercept plus FOLFIRI from March 2018 to July 2019. We investigated the association and predictive value of pretreatment blood inflammation and immune-based scores, including the neutrophil-to-lymphocyte ratio, platelet-to-lymphocyte ratio $(P L R)$, and lymphocyte-monocyte ratio, using their median values as cut-offs, in regard to disease control (DC), progression-free (PFS), and overall (OS) survival. Results: The number of patients in each treatment line of aflibercept was as follows: Second, 14 (66.7\%); third, four (19.0\%); fourth, two (9.5\%); eighth, one (4.8\%). The median number of aflibercept treatment courses was seven (range=2-17). The median followup time was 391 days. In univariate analysis, patients with DC had a significantly lower PLR than those without DC. Only the $P L R$ was significantly negatively associated with PFS, but not with OS. Multivariate analysis showed a significantly poor prognostic impact of a high PLR on PFS (hazard ratio=10.28; p=0.003). Conclusion: A low pretreatment PLR might be a predictor of aflibercept efficacy in patients with $m C R C$ and may be clinically useful for selecting patient responders.
\end{abstract}

This article is freely accessible online.

Correspondence to: Akihisa Matsuda, MD, Department of Gastrointestinal and Hepato-Biliary-Pancreatic Surgery, Nippon Medical School, 1-1-5 Sendagi, Bunkyo-ku, Tokyo 113-8603, Japan. Tel: +81 338222131, Fax: +81 356850989, e-mail: a-matsu@nms.ac.jp

Key Words: Platelet-to-lymphocyte ratio, metastatic colorectal cancer, aflibercept, predictive marker, prognosis, survival.
The prevalence of colorectal cancer (CRC) has been increasing in Japan; CRC has been the most common cancer since 2015, and over 50,000 patients die from this disease annually (1). CRC is diagnosed at an advanced stage in approximately $25 \%$ of patients, and $50 \%$ of patients with locally advanced disease develop metastasis (2). The prognosis of patients with metastatic CRC (mCRC) remains poor; however, combination therapy with molecular targeted agents and standard chemotherapy regimens has improved survival outcomes.

Aflibercept is a recombinant fusion protein comprising a vascular endothelial growth factor (VEGF)-binding portion, which selectively blocks the activity of VEGF-A, VEGF-B, and placental growth factor (3), differing from bevacizumab, which blocks only VEGF-A. In the global phase III VELOUR trial, after disease progression on a first-line oxaliplatin-based regimen, aflibercept plus 5-fluorouracil, leucovorin and irinotecan (FOLFIRI) compared with FOLFIRI alone demonstrated a significant survival benefit of 1.4 months in median overall survival (OS) (13.5 vs. 12.1 months, respectively; hazard ratio $(\mathrm{HR})=0.82,95 \%$ confidence interval $(\mathrm{CI})=0.71-0.94, p=0.003)$ and 2.2 months in median progression-free survival (PFS; 6.9 vs. 4.7 months, respectively; $\mathrm{HR}=0.76,95 \% \mathrm{CI}=0.66-0.87, p=0.0007)(4) . \mathrm{In}$ addition, the overall response rate (ORR) increased by $9 \%$ with the combination ( $19.8 \%$ vs. $11.1 \%$, respectively). However, a Japanese population was not included in this global study; therefore, a domestic single-arm phase II trial was conducted in Japan (EFC11885 trial) (5). Aflibercept with FOLFIRI in second-line therapy demonstrated acceptable outcomes of OS of 15.6 months, PFS of 5.4 months, ORR of $8.3 \%$, and a disease control (DC) rate of $80 \%$, findings that corroborated well with those in the global study, resulting in pharmaceutical approval of the drug in Japan in 2017. This therapy was included in the Japanese guidelines for the treatment of CRC in 2019 (6).

Little is known regarding effective predictive and prognostic biomarkers in aflibercept treatment, and no 
Table I. Characteristics of the included patients $(n=21)$.

\begin{tabular}{|c|c|c|}
\hline Characteristic & & Value \\
\hline Age, years & Median (range) & $68.4(51-81)$ \\
\hline \multirow[t]{2}{*}{ Gender, n (\%) } & Male & $15(71.4)$ \\
\hline & Female & $6(28.6)$ \\
\hline \multirow[t]{4}{*}{ ECOG PS, n (\%) } & 0 & $15(71.4)$ \\
\hline & 1 & $5(23.8)$ \\
\hline & 2 & $0(0)$ \\
\hline & 3 & $1(4.8)$ \\
\hline \multirow[t]{2}{*}{ Primary site, n (\%) } & Right-sided & $5(23.8)$ \\
\hline & Left-sided & $14(66.7)$ \\
\hline \multirow[t]{2}{*}{ Metastasis, n (\%) } & Synchronous & $15(71.4)$ \\
\hline & Metachronous & $6(28.6)$ \\
\hline \multirow{3}{*}{$\begin{array}{l}\text { Number of organs with } \\
\text { metastasis, } \mathrm{n}(\%)\end{array}$} & 1 & $7(33.3)$ \\
\hline & 2 & $9(42.9)$ \\
\hline & 3 & $5(23.8)$ \\
\hline \multirow[t]{2}{*}{ KRAS status, n (\%) } & Wild-type & $9(42.9)$ \\
\hline & Mutant & $12(57.1)$ \\
\hline \multirow{4}{*}{$\begin{array}{l}\text { Treatment line of } \\
\text { aflibercept, } \mathrm{n}(\%)\end{array}$} & 2 & $14(66.7)$ \\
\hline & 3 & $4(19.0)$ \\
\hline & 4 & $2(9.5)$ \\
\hline & 8 & $1(4.8)$ \\
\hline $\begin{array}{l}\text { Time from diagnosis to } \\
\text { aflibercept, months }\end{array}$ & Median (range) & $11.6(5.8-63.6)$ \\
\hline \multirow{2}{*}{$\begin{array}{l}\text { Prior treatment with } \\
\text { bevacizumab, n }(\%)\end{array}$} & Yes & $14(66.7)$ \\
\hline & No & 7 (66.7) \\
\hline $\begin{array}{l}\text { Number of aflibercept } \\
\text { treatment courses }\end{array}$ & Median (range) & $7(2-17)$ \\
\hline $\begin{array}{l}\text { Pre aflibercept treatment } \\
\text { CEA, } \mathrm{ng} / \mathrm{ml}\end{array}$ & Median (range) & $33.3(3.5-2278)$ \\
\hline $\begin{array}{l}\text { Pre aflibercept } \\
\text { treatment NLR }\end{array}$ & Median (range) & $3.82(0.68-12.43)$ \\
\hline $\begin{array}{l}\text { Pre aflibercept } \\
\text { treatment PLR }\end{array}$ & Median (range) & $193.2(105.6-433.3)$ \\
\hline $\begin{array}{l}\text { Pre aflibercept } \\
\text { treatment LMR }\end{array}$ & Median (range) & $2.33(1.13-5.75)$ \\
\hline
\end{tabular}

ECOG PS: Eastern Corporative Oncology Group performance status; NLR: neutrophil-to-lymphocyte ratio; PLR: platelet-to-lymphocyte ratio; LMR: lymphocyte-to-monocyte ratio.

objective marker has yet been identified. Inflammation and immune-based scores, such as the neutrophil-to-lymphocyte ratio (NLR), platelet-to-lymphocyte ratio (PLR), and lymphocyte-to-monocyte ratio (LMR), have been evaluated extensively regarding their relationship with cancer treatment outcomes (7-9). These markers are recognised as useful because of the low cost, ready availability, and easy interpretation. This study aimed to investigate the prognostic potential of inflammation and immune-based scores in aflibercept-treated patients with mCRC.

\section{Patients and Methods}

Patients. This was a single-institution retrospective study conducted at the Department of Surgery of Nippon Medical School Chiba Hokusoh Hospital with 21 patients with mCRC who were
Table II. Comparison between patients with and without disease control (DC).

\begin{tabular}{|c|c|c|c|}
\hline Characteristic & $\mathrm{DC}(\mathrm{n}=11)$ & No DC $(n=10)$ & $p$-Value \\
\hline \multicolumn{4}{|l|}{ Age, years } \\
\hline Median (range) & $68.0(51-81)$ & $68.0(61-75)$ & 0.815 \\
\hline \multicolumn{4}{|l|}{ Gender n $(\%)$} \\
\hline Male & $9(81.8)$ & $8(80.0)$ & $>0.99$ \\
\hline Female & $2(18.2)$ & $2(20.0)$ & \\
\hline \multicolumn{4}{|l|}{ ECOG PS, n (\%) } \\
\hline$\leq 1$ & $10(90.9) /$ & $10(100) /$ & $>0.99$ \\
\hline$\geq 2$ & $1(9.1)$ & $0(0)$ & \\
\hline \multicolumn{4}{|l|}{ Primary site, n (\%) } \\
\hline Right-sided & $2(18.2)$ & $3(10.0)$ & 0.635 \\
\hline Left-sided & $9(81.2)$ & $7(70.0)$ & \\
\hline \multicolumn{4}{|l|}{ Metastasis, n (\%) } \\
\hline Synchronous & $6(54.5)$ & $9(90.0)$ & 0.149 \\
\hline Metachronous & $5(45.4)$ & $1(10.0)$ & \\
\hline \multicolumn{4}{|c|}{$\begin{array}{l}\text { Number of organs } \\
\text { with metastasis, } n(\%)\end{array}$} \\
\hline 1 & $3(27.3)$ & $4(40.0)$ & 0.642 \\
\hline$\geq 2$ & $8(72.7)$ & $5(50.0)$ & \\
\hline \multicolumn{4}{|l|}{ KRAS status, $\mathrm{n}(\%)$} \\
\hline Wild-type & $4(36.4)$ & $5(50.0)$ & 0.670 \\
\hline Mutant & $7(63.6)$ & $5(50.0)$ & \\
\hline \multicolumn{4}{|c|}{$\begin{array}{l}\text { Treatment line of } \\
\text { aflibercept, } 2 / \geq 3, \mathrm{n}(\%)\end{array}$} \\
\hline 2 & 7 (63.6) & $7(70.0)$ & $>0.99$ \\
\hline$\geq 3$ & $4(36.4)$ & $3(30.0)$ & \\
\hline \multicolumn{4}{|c|}{$\begin{array}{l}\text { Prior treatment with } \\
\text { bevacizumab, } \mathrm{n}(\%)\end{array}$} \\
\hline Yes & $9(81.8)$ & $7(70.0)$ & 0.635 \\
\hline No & $2(18.2)$ & $3(30.0)$ & \\
\hline \multicolumn{4}{|l|}{$\begin{array}{l}\text { Pre aflibercept } \\
\text { treatment NLR }\end{array}$} \\
\hline Median (range) & $3.22(0.68-7.73)$ & $4.35(1.33-12.43)$ & 0.255 \\
\hline \multicolumn{4}{|l|}{$\begin{array}{l}\text { Pre aflibercept } \\
\text { treatment PLR }\end{array}$} \\
\hline Median (range) & $157.7(105.6-306.7)$ & $235.2(137.4-433.3)$ & 0.040 \\
\hline \multicolumn{4}{|l|}{$\begin{array}{l}\text { Pre aflibercept } \\
\text { treatment LMR }\end{array}$} \\
\hline Median (range) & $2.14(1.13-5.65)$ & $2.67(1.56-5.75)$ & 0.819 \\
\hline
\end{tabular}

ECOG PS: Eastern Corporative Oncology Group performance status; NLR: neutrophil-to-lymphocyte ratio; PLR: platelet-to-lymphocyte ratio; LMR: lymphocyte-to-monocyte ratio. Bold values indicate statistical significance.

consecutively treated with aflibercept plus FOLFIRI between March 2018 and July 2019. The clinical cut-off for data analyses was November 2019. The data were retrospectively collected from individual medical records. Patients received aflibercept $(4 \mathrm{mg} / \mathrm{kg}$ ) and FOLFIRI [400 mg/m $\mathrm{m}^{2}$ bolus of 5-fluorouracil (FU); 2400 $\mathrm{mg} / \mathrm{m}^{2}$ continuous infusion of $5-\mathrm{FU} ; 200 \mathrm{mg} / \mathrm{m}^{2}$ of levofolinate; 180 $\mathrm{mg} / \mathrm{m}^{2}$ of irinotecan] every 2 weeks. This regimen was discontinued at the time of disease progression or physician's judgement to cease.

Adverse events (AEs) were evaluated using the Common Terminology Criteria for Adverse Events, version 4.03 (10). Tumour response was evaluated by one investigator using version 1.1 of the Response Evaluation Criteria in Solid Tumours (RECIST) (11) in 
Table III. Progression-free (PFS) and overall (OS) survival according to predictive and prognostic factors.

\begin{tabular}{|c|c|c|c|c|c|}
\hline Variable & & $\begin{array}{c}\text { Median PFS }(95 \% \mathrm{CI}), \\
\text { months }\end{array}$ & $p$-Value & $\begin{array}{c}\text { Median OS }(95 \% \mathrm{CI}), \\
\text { months }\end{array}$ & $p$-Value \\
\hline \multirow[t]{2}{*}{ Age } & $<75$ Years $(\mathrm{n}=16)$ & $3.48(2.3-8.1)$ & 0.405 & $11.96(5.8-16.7)$ & 0.144 \\
\hline & $\geq 75$ Years $(n=5)$ & $4.63(2.30-\mathrm{NA})$ & & $17.87(3.2-\mathrm{NA})$ & \\
\hline \multirow[t]{2}{*}{ Gender } & Male $(n=15)$ & $5.19(2.3-7.4)$ & 0.249 & $14.92(5.78-\mathrm{NA})$ & 0.276 \\
\hline & Female $(\mathrm{n}=6)$ & 3.35 (2.3-NA) & & $6.93(2.3-\mathrm{NA})$ & \\
\hline \multirow[t]{2}{*}{ Primary site } & Right-sided ( $\mathrm{n}=5$ ) & $2.33(1.8-\mathrm{NA})$ & 0.305 & $12.0(2.3-\mathrm{NA})$ & 0.051 \\
\hline & Left-sided $(n=16)$ & $4.19(2.7-6.5)$ & & $17.30(6.5-\mathrm{NA})$ & \\
\hline \multirow[t]{2}{*}{ Metastasis } & Synchronous $(\mathrm{n}=15)$ & $2.96(2.3-5.2)$ & 0.401 & $11.96(5.6-\mathrm{NA})$ & 0.637 \\
\hline & Metachronous $(n=6)$ & 7.74 (2.7-NA) & & $14.92(4.0-\mathrm{NA})$ & \\
\hline \multirow{2}{*}{$\begin{array}{l}\text { Number of organs with } \\
\text { metastasis, n (\%) }\end{array}$} & $1(n=7)$ & $3.22(2.3-4.6)$ & 0.128 & $8.90(2.3-\mathrm{NA})$ & 0.449 \\
\hline & $\geq 2(n=14)$ & $5.26(2.3-8.7)$ & & $14.92(6.5-\mathrm{NA})$ & \\
\hline \multirow[t]{2}{*}{ KRAS status } & Wild-type $(n=9)$ & $2.76(2.3-8.1)$ & 0.282 & 17.87 (4.0-NA) & 0.382 \\
\hline & Mutant $(\mathrm{n}=12)$ & $5.26(2.3-8.7)$ & & $14.55(3.2-\mathrm{NA})$ & \\
\hline \multirow[t]{2}{*}{ Prior bevacizumab treatment } & Yes $(n=15)$ & $5.20(2.3-7.4)$ & 0.226 & $14.92(5.6-\mathrm{NA})$ & 0.487 \\
\hline & No $(n=6)$ & $2.76(1.8-\mathrm{NA})$ & & $6.93(4.0-\mathrm{NA})$ & \\
\hline \multirow[t]{2}{*}{ NLR (cutoff: 3.82$)^{*}$} & $\operatorname{High}(\mathrm{n}=10)$ & $2.66(1.8-4.6)$ & 0.395 & $13.26(2.3-\mathrm{NA})$ & 0.797 \\
\hline & Low $(n=11)$ & $5.32(2.8-8.1)$ & & $14.92(5.6-\mathrm{NA})$ & \\
\hline \multirow[t]{2}{*}{ PLR (cutoff: 193.2)* } & High $(n=11)$ & $2.66(2.3-3.2)$ & $<0.001$ & $8.90(3.2-\mathrm{NA})$ & 0.145 \\
\hline & Low $(n=10)$ & $7.31(2.3-10.1)$ & & $14.92(5.6-\mathrm{NA})$ & \\
\hline \multirow[t]{2}{*}{ LMR (cutoff: 2.33)* } & $\operatorname{High}(\mathrm{n}=11)$ & $3.22(2.3-8.2)$ & 0.928 & $14.92(2.3-\mathrm{NA})$ & 0.583 \\
\hline & Low $(n=10)$ & $4.98(1.8-7.4)$ & & 14.55 (4.0-NA) & \\
\hline
\end{tabular}

CI: Confidence interval; NA: not reached; ECOG PS: Eastern Corporative Oncology Group performance status; NLR: neutrophil-to-lymphocyte ratio; PLR: platelet-to-lymphocyte ratio; LMR: lymphocyte-to-monocyte ratio. *Median value. Bold values indicate statistical significance.

patients with measurable disease at baseline. The white blood cell count, including the fractions of neutrophils, lymphocytes, and monocytes, and platelet count were measured at an institutional laboratory. The pre-aflibercept treatment NLR, PLR, and LMR were calculated for each patient.

PFS was estimated as the time between the first aflibercept administration and either disease progression or death, and OS was defined as the time until death. Patients were censored at their last follow-up visit if they were free of disease progression or alive, respectively, for PFS or OS analyses. The Kaplan-Meier method was used to calculate PFS and OS, and differences between the two patient groups were analysed using the log-rank test. Statistical analyses were performed using R, version 3.1.0 (R Foundation for Statistical Computing, Vienna, Austria). Continuous variables were expressed as medians and ranges and were compared using twotailed Student's $t$-test and the Mann-Whitney $U$-test. Discrete variables were compared using chi-squared and Fisher's exact tests. Variables for which $p<0.2$ in univariate analysis were entered into the multivariate Cox proportional hazard model. Values of $p<0.05$ were considered significant. All of the procedures were conducted according to the Declaration of Helsinki, and the study protocol was approved by the Ethics Committee of Nippon Medical School Chiba Hokusoh Hospital (Chiba, Japan) (Approval No. 747).

\section{Results}

Patient characteristics and aflibercept treatment. Twentyone patients [median age $=68.0($ range $=51-81)$ years; 15 male (71.4\%)] with mCRC were treated with aflibercept plus FOLFIRI, including 14 with a left-sided primary tumour
(66.7\%), one (4.8\%) with an Eastern Cooperative Oncology Group Performance Status (ECOG PS) $\geq 2$, nine $(42.9 \%$ ) with KRAS wild-type tumours, and $14(66.7 \%)$ with prior bevacizumab treatment. Fourteen (67\%) patients had two or more metastatic sites. Two-thirds of patients were treated with aflibercept plus FOLFIRI as second-line therapy. The median number of aflibercept treatment courses was seven (range=2-17). No patient was lost to follow-up. The median follow-up from treatment initiation to the last treatment or death was 391 days. Fourteen patients $(66.7 \%)$ received one or more further chemotherapeutic treatments. Eight patients $(38.1 \%)$ were still alive at the data cut-off. The characteristics are shown in Table I.

Role of the PLR as a biomarker in aflibercept treatment. All the included patients had measurable disease at baseline but one patient was not evaluated by computed tomography owing to severe disease progression. The ORR, which included no complete response and one patient with partial response, was $4.7 \%$. The DC rate, with one partial response and 20 patients with stable disease, was $52.4 \%$. The overall median PFS and OS were 3.8 months and 13.0 months, respectively. In order to explore the factors related to the DC efficacy of aflibercept, the patients were divided into two groups, with DC $(n=11$, $52.4 \%)$ and without DC $(\mathrm{n}=10,47.6 \%)$. Among the variables, the pretreatment PLR in the DC group was significantly lower than that in the group without DC [median=157.7 

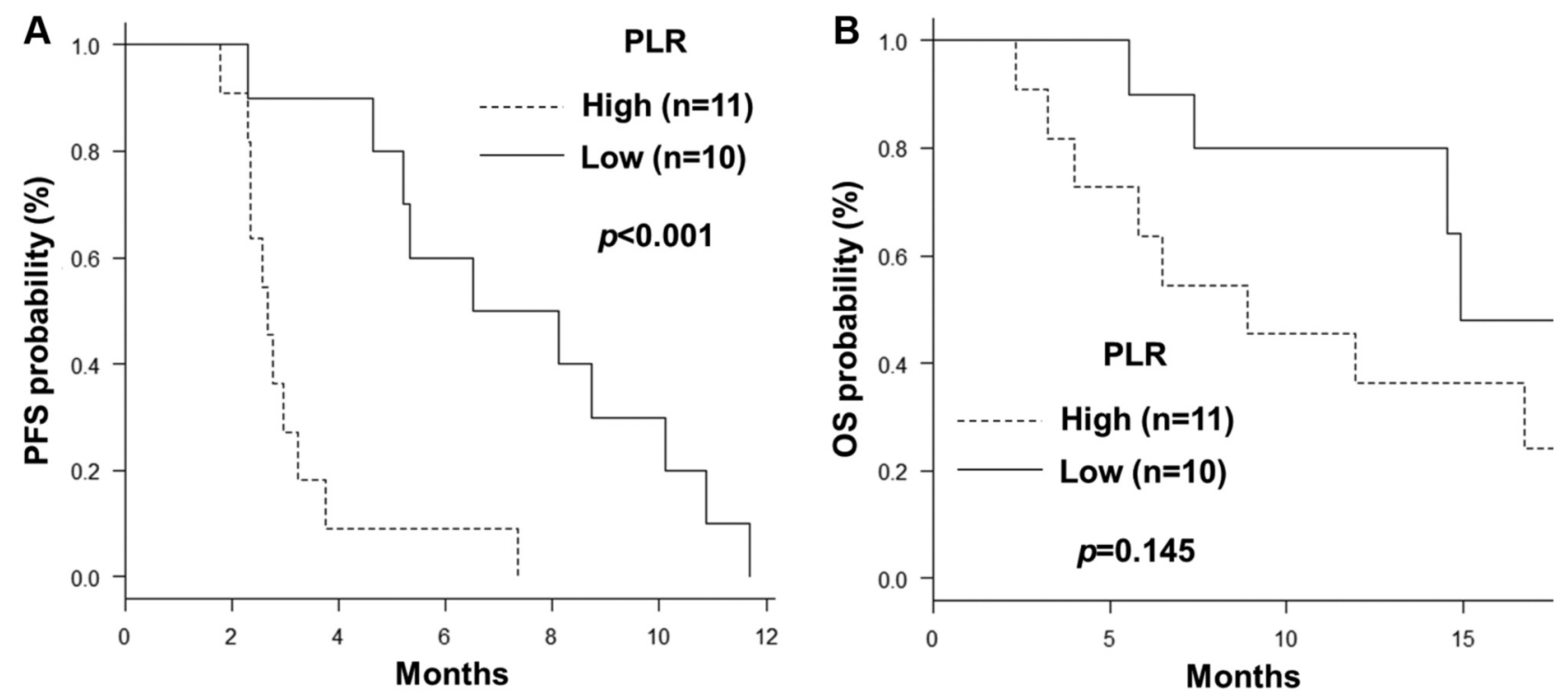

Figure 1. Kaplan-Meier curves showing progression-free (A) and overall (B) survival according to the platelet-to-lymphocyte ratio (PLR) [cut-off: 193.2 (median)].

(range=105.6-306.7) and median=235.2 (range=137.4-433.3), respectively, $p=0.040]$. However, other variables, including the pretreatment NLR and LMR, showed no significant differences between the groups (Table II).

The median values of the NLR, PLR, and LMR were 3.82, 193.2, and 2.33, respectively, and these cut-off values were used for further analyses. Univariate exploratory analyses were conducted to identify predictive and prognostic factors for PFS and OS (Table III). Among the clinical variables, including age, gender, primary site, synchronous or metachronous metastasis, number of organs with metastases, KRAS status, and prior bevacizumab treatment, left-sided primary tumour tended to confer a longer OS than right-sided disease (17.30 vs. 12.0 months, respectively; $p=0.051$ ), although the difference was not statistically significant. Other comparisons showed no significant differences in PFS and OS analyses. Among the haematological inflammation and immune-based scores, a high PLR was associated with a significantly shorter PFS and a trend for a shorter OS than a low PLR (PFS: 2.66 vs. 5.32 months, respectively; $p<0.001$; OS: 8.90 vs. 14.92 months, respectively; $p=0.145$ ) (Figure $1 \mathrm{~A}$ and $\mathrm{B}$, respectively). However, the NLR and LMR were not associated with PFS and OS. In the Cox proportional hazard model for PFS using the variables number of organs with metastases and PLR, a high PLR was associated with poorer PFS and was identified as an independent prognostic factor (Table IV).

Safety and comparison between a urinary qualitative test and the urinary protein/creatinine ratio. Sixteen patients (76.2\%) developed AEs of grade 3 or higher. Among the haematological AEs, the incidences of grade 3 or higher leukopenia, neutropenia, anaemia, and thrombocytopenia were $28.6 \%, 23.8 \%, 4.8 \%$, and $23.8 \%$, respectively. Among the non-haematological AEs, the incidences of grade 3 or higher anorexia, nausea, fatigue, and hypertension were $23.8 \%, 9.5 \%, 4.8 \%$, and $23.8 \%$, respectively. Grade 3 or higher proteinuria occurred in $4.8 \%$ of patients, and proteinuria of any grade occurred in $76.2 \%$ of patients.

Concerning proteinuria, both a qualitative test using a dipstick and the urinary protein/creatinine ratio (UPCR) were assessed at our Institute. Among 157 urine samples representing all administrations of aflibercept in the included patients, 27 measurements (17.2\%) showed a UPCR $\geq 2$, which is a criterion for withdrawal of drug administration. The association between the qualitative test and UPCR is presented in Figure 2. The median values of UPCR increased with increasing qualitative test grade $(-/ \pm: 0.13,1+: 0.56$, $2+: 1.41,3+/ 4+: 2.57)$. The prevalence of UPCR $\geq 2$ was $2.0 \%(2 / 99)$ in samples with qualitative test grades $-/ \pm$ and $1+$, and $43.1 \%(25 / 58)$ in those with grades $2+$ and $3+/ 4+$.

\section{Discussion}

This observational retrospective study demonstrated that, among patients with refractory mCRC treated with aflibercept plus FOLFIRI, the pretreatment PLR was significant associated with both DC and PFS in univariate analyses, and PFS in multivariate analysis. This finding suggests that the pretreatment blood inflammation and immune-based score, PLR, might be a prognostic or 
Table IV. Cox proportional hazard model for progression-free survival (PFS).

\begin{tabular}{lcccc}
\hline Variable & \multicolumn{4}{c}{ PFS } \\
\cline { 2 - 5 } & Subgroup & HR & $95 \%$ CI & $p$-Value \\
\hline Number of organs & 1 & 1 (Reference) & & \\
with metastasis & $\geq 2$ & 2.01 & $0.54-7.55$ & 0.301 \\
PLR (cutoff: 193.2) & Low & 1 (Reference) & & \\
& High & 10.28 & $2.20-47.91$ & $\mathbf{0 . 0 0 3}$ \\
\hline
\end{tabular}

HR: Hazard ratio; CI: confidence interval; PLR: platelet-to-lymphocyte ratio. Bold value indicates statistical significance.

predictive biomarker. To our best knowledge, this is the first study to investigate the role of the PLR as a clinical biomarker in patients treated with aflibercept with a median follow-up of over 1 year.

Growing evidence suggests that exaggerated inflammatory host responses are reflected in poor surgical outcomes and hypo-responsiveness to systemic chemotherapy in various cancer types, including CRC (7, 9, 12, 13). Systemic inflammatory host responses contribute to critical roles through all stages of tumourigenesis and induce immunosuppression, angiogenesis, inhibition of apoptosis, and DNA damage, promoting metastatic spread $(14,15)$.

A high PLR represents a relatively elevated platelet count and lymphocyte depletion and is considered a negative prognostic marker in several types of cancer (16-18). In the milieu of systemic inflammation, pro-inflammatory mediators, such as interleukin (IL)-1 and IL6, can stimulate thrombocytosis. Platelets can induce angiogenesis from enhanced VEGF production (19). Thrombocytosis reflects both systemic inflammation and increased tumour activities, which facilitate tumour invasion and metastasis.

Lymphocytes, which participate in adaptive immune responses, can be recruited from the peripheral circulation to tumour tissue to activate transcription factors of inflammatory cells and tumour cells, such as nuclear factor$\mathrm{kB}$, followed by the production of pro-inflammatory mediators, which are mainly released from $\mathrm{CD}^{+}{ }^{+}$lymphocytes (20). Our results showed that the PLR, but not the respective absolute platelet and lymphocyte counts, had a significant effect on the treatment efficacy and survival (data not shown). This phenomenon implies the importance of the balance between inflammation and the immunological status in individual patients.

However, the association between the PLR and outcomes in patients with CRC remains to be clarified. Peng et al. reported in their meta-analysis that an elevated PLR was not associated with disease-free survival in patients undergoing curative surgery but was associated with poor survival in

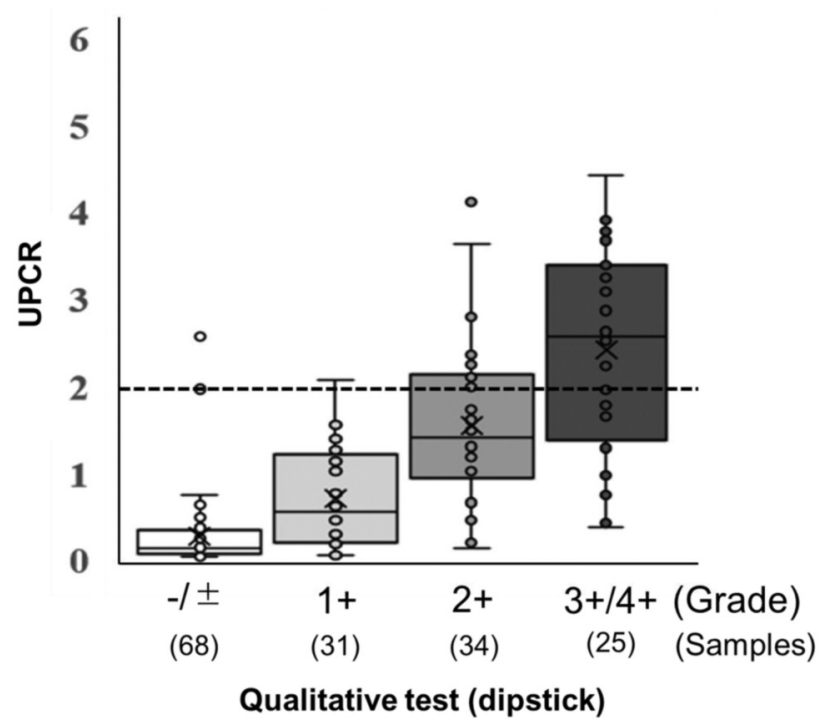

Figure 2. Association between the urinary qualitative test using a dipstick and protein/creatinine ratio (UPCR). The data are expressed as means \pm standard deviation. The median values are indicated by horizontal lines, and the lower and upper edges of the boxes indicate the $25^{\text {th }}$ and $75^{\text {th }}$ percentiles, respectively.

patients with metastatic disease (21). The inflammation and immune status in patients with CRC undergoing curative surgery and those with metastatic CRC might be different. Factors such as the tumour volume, prior treatment, and cancer cachexia, may contribute to these differences and influence the utility of the PLR as a prognostic biomarker. Consistent with this theory, in the metastatic setting, the pretreatment PLR was significantly associated with DC and PFS, but not with OS. Yang et al. also reported similar results that a higher PLR was significantly associated with poorer PFS, but the difference was not statistically significant for OS in patients with $\mathrm{mCRC}$ who received cetuximab (22). The underlying mechanism of the superior predictive efficacy of the PLR compared with other similar markers, such as the NLR and LMR in this study, remains unknown. However, a previously reported direct interaction between aflibercept and platelets may provide a clue to resolve the question. Sobolewska et al. (23) reported that the co-treatment of platelets with aflibercept resulted in increased platelet activation and up-regulation of fibrinogen receptor GPIIb/IIIa, but no effect on platelet aggregation.

The absence of validated clinical biomarkers to predict the efficacy of aflibercept is a weakness hindering optimal treatment management with this agent. Lambrechts et al. first reported the predictive biomarker of blood IL8, whose high levels are associated with poorer PFS (24). A recent study by Hamaguchi et al. identified eight potential biomarkers whose baseline levels were correlated with OS, including IL8 (25). However, clinicians cannot easily apply these markers for 
routine measurement. Montes et al. showed hypertension development during aflibercept therapy to be associated with longer PFS and OS but the predictive impact of hypertension might be attributed to immortal time bias (26).

Asymptomatic proteinuria is a common $\mathrm{AE}$ in patients treated with anti-angiogenic inhibitors. The management of drug-induced proteinuria is an important issue because dosage reduction and irreversible renal damage can occur. Peng et al., in a meta-analysis of various cancers treated with aflibercept, reported that the risk of developing proteinuria with aflibercept was substantially higher than that with bevacizumab (27). The UPCR was recently used to estimate daily protein excretion because of its convenience and simplicity (28). The UPCR or urine qualitative test using a dipstick is recommended to monitor proteinuria and decide on dose reduction and cessation in aflibercept treatment (cut-off: UPCR $\geq 2$ ). However, the UPCR is not always routinely measured at all institutions and only the urine qualitative test using a dipstick $(\geq 2+)$ is applied in that case. Our results showed that the UPCR increased with a higher qualitative test grade, but only $43.1 \%$ of measurements with a qualitative test using a dipstick $(\geq 2+)$ demonstrated a UPCR $\geq 2$. This suggests that UPCR measurements are required to prevent unnecessary dose reduction and cessation in order to maximise the treatment effect of aflibercept.

The outcomes in this study cohort treated with aflibercept plus FOLFIRI were an OS of 13.0 months, a PFS of 3.8 months, an ORR of $4.7 \%$, and a DC rate of $52.4 \%$, which are lower than the outcomes of the VELOUR and EFC11885 trials $(4,5)$. A plausible reason is that our cohort included many patients treated with aflibercept beyond the second line (33.3\%, 7/21). Recently, Auvray et al. reported outcomes beyond the second-line setting, with an OS of 7.6 months, a PFS of 3.3 months, an ORR of $6.9 \%$, and a DC rate of $50.0 \%$ (29); ours findings were similar or better.

The major limitations of our study are its retrospective nature, small sample size, and single-centre, single-arm Japanese-based cohort design. Hence, whether the PLR is prognostic could not be determined, only that it is potentially prognostic for the treatment response. The validity of the applied PLR cut-off, the median value and superior cut-off, which is an absolute value, should be investigated in a future prospective study with a larger sample size.

In conclusion, we describe the prognostic potential of the pretreatment PLR in patients with mCRC treated with aflibercept plus FOLFIRI. This easily accessible biomarker would support clinicians in achieving appropriate drug treatment for these patients in daily practice.

\section{Conflicts of Interest}

The Authors declare no conflicts of interest regarding this article.

\section{Authors' Contributions}

Study concept and design: A. Matsuda and S. Matsumoto. Acquisition of data: A. Matsuda, E. Shinozuka, and K. Sekiguchi. Analysis and interpretation of data: A. Matsuda, T. Yamada, S. Matsumoto, S. Shinji, R. Ota, and H. Sonoda. Drafting of the article: A. Matsuda and T. Yamada. Study supervision: H. Suzuki and $\mathrm{H}$. Yoshida.

\section{Acknowledgements}

The Authors thank Nicole Okoh, Ph.D., from Edanz Group (https://en-author-services.edanzgroup.com/) for editing a draft of this article.

\section{References}

1 Service CI: Projected Cancer Statistics, 2016. Available at http://ganjoho.Jp/en/public/statistics/short_pred.Html [Last accessed on April 15, 2020]

2 Van Cutsem E, Cervantes A, Nordlinger B, Arnold D and Group EGW: Metastatic colorectal cancer: ESMO clinical practice guidelines for diagnosis, treatment and follow-up. Ann Oncol 25 Suppl 3: iii1-9, 2014. PMID: 25190710. DOI: 10.1093/ annonc/mdu260

3 Gaya A and Tse V: A preclinical and clinical review of aflibercept for the management of cancer. Cancer Treat Rev 38(5): 484-493, 2012. PMID: 22264850. DOI: 10.1016/j.ctrv. 2011.12.008

4 Van Cutsem E, Tabernero J, Lakomy R, Prenen H, Prausova J, Macarulla T, Ruff P, van Hazel GA, Moiseyenko V, Ferry D, McKendrick J, Polikoff J, Tellier A, Castan R and Allegra C: Addition of aflibercept to fluorouracil, leucovorin, and irinotecan improves survival in a phase iii randomized trial in patients with metastatic colorectal cancer previously treated with an oxaliplatin-based regimen. J Clin Oncol 30(28): 3499-3506, 2012. PMID: 22949147. DOI: 10.1200/JCO.2012.42.8201

5 Denda T, Sakai D, Hamaguchi T, Sugimoto N, Ura T, Yamazaki K, Fujii H, Kajiwara T, Nakajima TE, Takahashi S, Otsu S, Komatsu Y, Nagashima F, Moriwaki T, Esaki T, Sato T, Itabashi M, Oki E, Sasaki T, Sunaga Y, Ziti-Ljajic S, Brillac C and Yoshino T: Phase II trial of aflibercept with FOLFIRI as a second-line treatment for japanese patients with metastatic colorectal cancer. Cancer Sci 110(3): 1032-1043, 2019. PMID: 6398889. DOI: $10.1111 /$ cas.13943

6 Hashiguchi Y, Muro K, Saito Y, Ito Y, Ajioka Y, Hamaguchi T, Hasegawa $K$, Hotta $K$, Ishida $H$, Ishiguro $M$, Ishihara $S$, Kanemitsu Y, Kinugasa Y, Murofushi K, Nakajima TE, Oka S, Tanaka T, Taniguchi H, Tsuji A, Uehara K, Ueno H, Yamanaka T, Yamazaki K, Yoshida M, Yoshino T, Itabashi M, Sakamaki K, Sano K, Shimada Y, Tanaka S, Uetake H, Yamaguchi S, Yamaguchi N, Kobayashi H, Matsuda K, Kotake K, Sugihara K, Japanese Society for Cancer of the Colon and Rectum: Japanese Society for Cancer of the Colon and Rectum (JSCCR) guidelines 2019 for the treatment of colorectal cancer. Int J Clin Oncol 25(1): 1-42, 2020. PMID: 6946738. DOI: 10.1007/s10147-019-01485-Z

7 Matsuda A, Yamada T, Matsumoto S, Sakurazawa N, Kawano Y, Shinozuka E, Sekiguchi K, Suzuki $\mathrm{H}$ and Yoshida H: Pretreatment neutrophil-to-lymphocyte ratio predicts survival after TAS-102 treatment of patients with metastatic colorectal 
cancer. Anticancer Res 39(8): 4343-4350, 2019. PMID: 31366528. DOI: 10.21873 /anticanres.13602

8 Nagasaki T, Akiyoshi T, Fujimoto Y, Konishi T, Nagayama S, Fukunaga Y and Ueno M: Prognostic impact of neutrophil-tolymphocyte ratio in patients with advanced low rectal cancer treated with preoperative chemoradiotherapy. Dig Surg 32(6): 496-503, 2015. PMID: 26544755. DOI: $10.1159 / 000441396$

9 Yodying H, Matsuda A, Miyashita M, Matsumoto S, Sakurazawa $\mathrm{N}$, Yamada $\mathrm{M}$ and Uchida E: Prognostic significance of neutrophil-to-lymphocyte ratio and platelet-to-lymphocyte ratio in oncologic outcomes of esophageal cancer: A systematic review and meta-analysis. Ann Surg Oncol 23(2): 646-654, 2016. PMID: 26416715. DOI: 10.1245/s10434-015-4869-5

10 Department of Health and Human Services National Institute of Health: Common Terminology Criteria for Adverse Events (CTCAE)v4. 03 2010. Available at: https://www.eortc.be/ services/doc/ctc/CTCAE_4.03_2010-06-14_QuickReference_ 5x7.pdf [Last accessed on April 29, 2020]

11 Eisenhauer EA, Therasse P, Bogaerts J, Schwartz LH, Sargent D, Ford R, Dancey J, Arbuck S, Gwyther S, Mooney M, Rubinstein L, Shankar L, Dodd L, Kaplan R, Lacombe D and Verweij J: New response evaluation criteria in solid tumours: Revised RECIST guideline (version 1.1). Eur J Cancer 45(2): 228-247, 2009. PMID: 19097774. DOI: 10.1016/j.ejca.2008.10.026

12 Kamonvarapitak T, Matsuda A, Matsumoto S, Jamjittrong S, Sakurazawa N, Kawano Y, Yamada T, Suzuki H, Miyashita M and Yoshida H: Preoperative lymphocyte-to-monocyte ratio predicts postoperative infectious complications after laparoscopic colorectal cancer surgery. Int J Clin Oncol 25(4): 633-640, 2020. PMID: 31781993. DOI: 10.1007/s10147-019-01583-y

13 Matsuda A, Yamada M, Matsumoto S, Sakurazawa N, Kawano Y, Sekiguchi K, Yamada T, Matsutani T, Miyashita M and Yoshida H: Blood galectin-3 levels predict postoperative complications after colorectal cancer surgery. J Nippon Med Sch 86(3): 142-148, 2019. PMID: 31292325. DOI: 10.1272/jnms. JNMS.2019 86-302

14 Coussens LM and Werb Z: Inflammation and cancer. Nature 420(6917): 860-867, 2002. PMID: 2803035. DOI: 10.1038/ nature 01322

15 Grivennikov SI, Greten FR and Karin M: Immunity, inflammation, and cancer. Cell 140(6): 883-899, 2010. PMID: 2866629. DOI: $10.1016 /$ j.cell.2010.01.025

16 Guo T, Krzystanek M, Szallasi Z and Szallasi A: Thrombocytosis portends adverse prognostic significance in patients with stage II colorectal carcinoma. F1000Res 3: 180, 2014. PMID: 4240242. DOI: 10.12688/f1000research.4856.2

17 Ikeda M, Furukawa H, Imamura H, Shimizu J, Ishida H, Masutani S, Tatsuta M and Satomi T: Poor prognosis associated with thrombocytosis in patients with gastric cancer. Ann Surg Oncol 9(3): 287-291, 2002. PMID: 11923136. DOI: 10.1007/ bf02573067

18 Voutsadakis IA: Thrombocytosis as a prognostic marker in gastrointestinal cancers. World J Gastrointest Oncol 6(2): 34-40, 2014. PMID: 3926972. DOI: 10.4251/wjgo.v6.i2.34

19 Cedervall J, Hamidi A and Olsson AK: Platelets, nets and cancer. Thromb Res 164 Suppl 1: S148-S152, 2018. PMID: 29703474. DOI: 10.1016/j.thromres.2018.01.049

20 Mantovani A, Allavena P, Sica A and Balkwill F: Cancer-related inflammation. Nature 454(7203): 436-444, 2008. PMID: 18650914. DOI: 10.1038 /nature07205
21 Peng HX, Lin K, He BS, Pan YQ, Ying HQ, Hu XX, Xu T and Wang SK: Platelet-to-lymphocyte ratio could be a promising prognostic biomarker for survival of colorectal cancer: A systematic review and meta-analysis. FEBS Open Bio 6(7): 742750, 2016. PMID: 4932454. DOI: 10.1002/2211-5463.12083

22 Yang J, Guo X, Wang M, Ma X, Ye X and Lin P: Pre-treatment inflammatory indexes as predictors of survival and cetuximab efficacy in metastatic colorectal cancer patients with wild-type RAS. Sci Rep 7(1): 17166, 2017. PMID: 5719445. DOI: 10.1038/s41598-017-17130-6

23 Sobolewska B, Golenko J, Poeschel S, Grimmel C, Gatsiou A, Sopova K, Biedermann T, Schenke-Layland K, Stellos K and Ziemssen F: Influence of aflibercept on platelet activation profile. Exp Eye Res 175: 166-172, 2018. PMID: 29908884. DOI: 10.1016/j.exer.2018.06.009

24 Lambrechts D, Thienpont B, Thuillier V, Sagaert X, Moisse M, Peuteman G, Pericay C, Folprecht G, Zalcberg J, Zilocchi C, Margherini E, Chiron M and Van Cutsem E: Evaluation of efficacy and safety markers in a phase II study of metastatic colorectal cancer treated with aflibercept in the first-line setting. Br J Cancer 113(7): 1027-1034, 2015. PMID: 4651136. DOI: 10.1038/bjc.2015.329

25 Hamaguchi T, Denda T, Kudo T, Sugimoto N, Ura T, Yamazaki K, Fujii H, Kajiwara T, Nakajima TE, Takahashi S, Otsu S, Komatsu Y, Nagashima F, Moriwaki T, Esaki T, Sato T, Itabashi M, Oki E, Sasaki T, Chiron M and Yoshino T: Exploration of potential prognostic biomarkers in aflibercept plus FOLFIRI in Japanese patients with metastatic colorectal cancer. Cancer Sci 110(11): 3565-3572, 2019. PMID: 6825011. DOI: $10.1111 /$ cas. 14198

26 Fernandez Montes A, Martinez Lago N, Covela Rua M, de la Camara Gomez J, Gonzalez Villaroel P, Mendez Mendez JC, Jorge Fernandez M, Salgado Fernandez M, Reboredo Lopez M, Quintero Aldana G, Luz Pellon Augusto M, Grana Suarez B and Garcia Gomez J: Efficacy and safety of FOLFIRI/aflibercept in second-line treatment of metastatic colorectal cancer in a realworld population: Prognostic and predictive markers. Cancer Med 8(3): 882-889, 2019. PMID: 6434192. DOI: 10.1002/ cam4.1903

27 Peng L, Zhao Q, Ye X, Zhou Y, Hu D and Zheng S: Incidence and risk of proteinuria with aflibercept in cancer patients: A meta-analysis. PLoS One 9(11): e111839, 2014. PMID: 4218823. DOI: 10.1371/journal.pone.0111839

28 Keane WF and Eknoyan G: Proteinuria, albuminuria, risk, assessment, detection, elimination (PARADE): A position paper of the national kidney foundation. Am J Kidney Dis 33(5): 1004 1010 , 1999. PMID: 10213663. DOI: 10.1016/s02726386(99)70442-7

29 Auvray M, Tougeron D, Auclin E, Moulin V, Artru P, Hautefeuille V, Hammel P, Lecomte T, Locher C, Sickersen G, Coriat R, Lecaille C, Vernerey D, Taieb J and Pernot S: Efficacy and safety of aflibercept in combination with chemotherapy beyond second-line therapy in metastatic colorectal carcinoma patients: An AGEO multicenter study. Clin Colorectal Cancer 19(1): 39-47 e35, 2020. PMID: 31648924. DOI: 10.1016/ j.clcc 2019.08 .003

Received April 10, 2020

Revised April 24, 2020

Accepted April 29, 2020 